\title{
Promotion of the Journal of Exercise Rehabilitation to the international level based on journal metrics
}

\author{
Sun Huh* \\ Department of Parasitology and Institute of Medical Education, College of Medicine, Hallym University, Chuncheon, Korea
}

The aim of this study was to use journal metrics to confirm that the Journal of Exercise Rehabilitation has been promoted to the international level after changing its language to English-only in April 2013. Journal metrics, including the number of articles per year, countries of authors, countries of the editorial board members, impact factor, total citations, and the Hirsch index, were counted or calculated based on the journal homepage and the Web of Science Core Collection in December 2016. The number of citable articles was 52,62,59, and 74 in $2013,2014,2015$, and 2016, respectively. All authors were from Korea in 2013 and 2014, but the authors were from 11 countries in 2015 and from 16 countries in 2016. The editorial board members are currently from 11 countries. The impact factor without self-citations for 2015 was 0.912 , corresponding to a Journal Citation Reports ranking of $32.9 \%$ out of 82 journals in the category of sport sciences. The total citations increased from 1 in 2013 to 130 in 2016. This journal was cited in 208 other source journals in the Web of Science. The citing authors were from 47 countries. The Hirsch index was 7, and review articles were the most frequently cited articles. The above results show a rapid development to the international level over 4 years. The introduction of digital technology to journals to improve their accessibility across multiple platforms is recommended.

Keywords: Bibliometrics, Journal impact factor, Language, Republic of Korea, Sports

\section{INTRODUCTION}

The Journal of Exercise Rebabilitation is the official journal of the Korean Society of Exercise Rehabilitation. It continues the Korean Journal of Exercise Rehabilitation from the April 2013 issue (volume 9, number 2) after Dr. Khae-Hawn Kim was recruited as Editor-in-Chief. At that time, the journal language was changed to English-only. Its scope includes basic research on exercise rehabilitation, clinical research on exercise rehabilitation, exercise rehabilitation pedagogy, exercise rehabilitation education, exercise rehabilitation psychology, and exercise rehabilitation welfare. The editorial board members consist of sports scientists, physicians, and rehabilitation specialists. Its aims are unique because the focus of the journal is the collaboration of sports scientists and physicians to improve human health through the development of exercise rehabilitation. In this article, I would like to present evidence that the journal has been promoted to the international level based on

journal metrics, including citable articles by year, the multinational composition of the editorial board members and authors, total citations, the impact factor, the source titles and countries of citing authors, and the Hirsch index (H-index) based on the Web of Science Core Collection database maintained by Clarivate Analytics, which succeeded the former Thomson Reuters Intellectual Property and Science Business in October 2016.

\section{MATERIALS AND METHODS}

The number of citable and noncitable articles was obtained from the journal's homepage, http://e-jer.org/. The countries of the editorial board members and authors were counted as well. Total citations were defined as the number of total citations in a given year regardless of the publication year of the journal. The impact factor was calculated manually according to the following formula (Huh, 2016a).

${ }^{*}$ Corresponding author: Sun Huh (ib http://orcid.org/0000-0002-8559-8640 Department of Parasitology and Institute of Medical Education, Hallym University College of Medicine, 1 Hallimdaehak-gil, Chuncheon 24252, Korea Tel: +82-33-248-2652, Fax: +82-33-241-1672, E-mail: shuh@hallym.ac.kr Received: December 11, 2016 / Accepted: December 19, 2016
This is an Open Access article distributed under the terms of the Creative Commons Attribution Non-Commercial License (http://creativecommons.org/licenses/by-nc/4.0/) which permits unrestricted non-commercial use, distribution, and reproduction in any medium, provided the original work is properly cited. 
Number of citable articles of the target journal published in $2013=\mathrm{A}$

Number of citable articles of the target journal published in $2014=\mathrm{B}$

Number of citations of the target journal published in 2013 from the Web of Science Core Collection in 2015=C

Number of citations of the target journal published in 2014 from the Web of Science Core Collection in 2015= D

2015 impact factor $=(\mathrm{C}+\mathrm{D}) /(\mathrm{A}+\mathrm{B})$

The source titles were the journal titles that cited the Journal of Exercise Rehabilitation, and the country of the citing authors was defined as the country of the authors' affiliation. The H-index was defined as "the number of papers with citation number $\geq b$ " and "it has index $b$ if $h$ of its $N_{p}$ papers have at least $h$ citations each

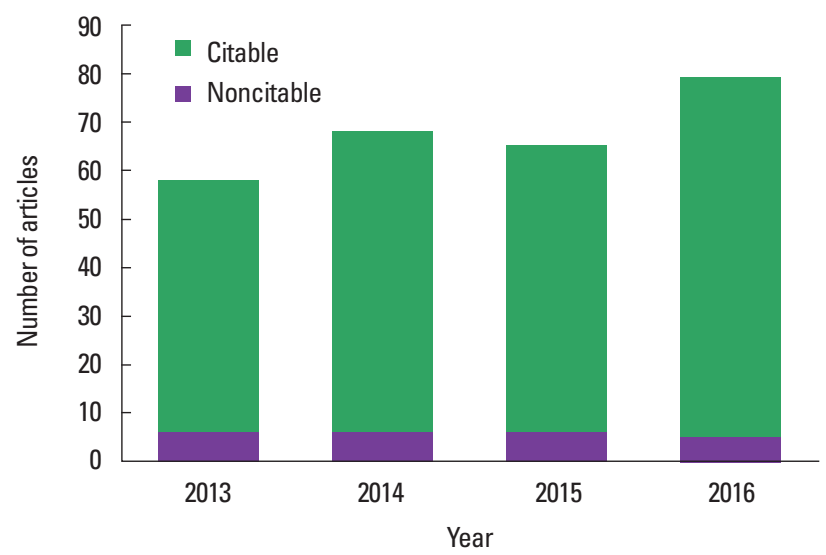

Fig. 1. Number of citable and noncitable articles published from 2013 to October 2016 in the Journal of Exercise Rehabilitation (as of December 3, 2016). Available from: http://e-jer.org/.

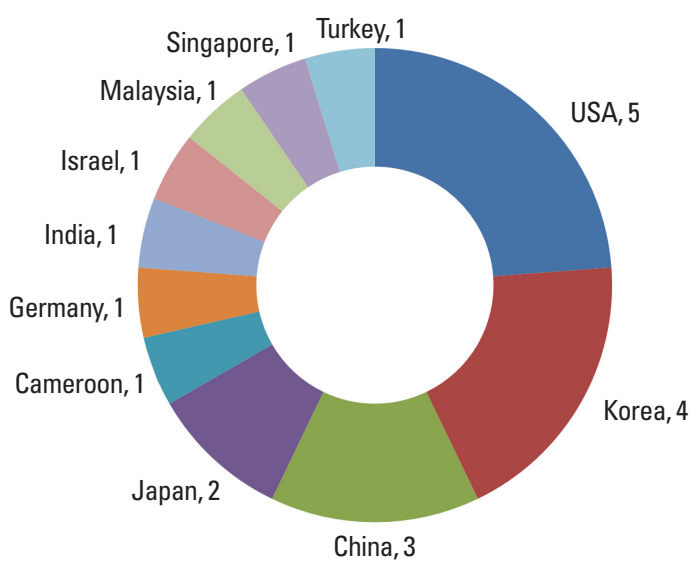

Fig. 2. Countries of the editorial board members of the Journal of Exercise Rehabilitation (as of December 3, 2016). Available from: http://e-jer.org/. and the other $\left(N_{p}-b\right)$ papers have $\leq b$ citations each" (Hirsch, 2005). The publication type of frequently cited articles was recorded. Citation analysis was based on the Web of Science Core Collection database (as of December 3, 2016).

\section{RESULTS}

The number of articles was consistent from 2013 to the present (Fig. 1). The proportion of noncitable articles was $9.3 \%$. The editorial board members were found to be from 11 countries (Fig. 2). Eleven articles were published from 10 countries in 2015 excluding Korea, and 24 articles were published from 15 countries in 2016 excluding Korea. The countries of non-Korean authors' affiliations in 2015 and 2016 are presented in Fig. 3. Total citations are presented in Fig. 4. They increased from 1 in 2013 to 130 in 2016. The impact factors for 2015 and 2016 were calculated as follows:

Number of citable articles in 2013: 52

Number of citable articles in 2014: 62

Total: 114

Number of citations of 2013 articles from Web of Science journals in 2015: 54

Number of citations of 2014 articles from Web of Science journals in 2015: 50

Total: 104

2015 impact factor $=104 / 114=0.912$

Number of citable articles in 2014: 62

Number of citable articles in 2015: 59

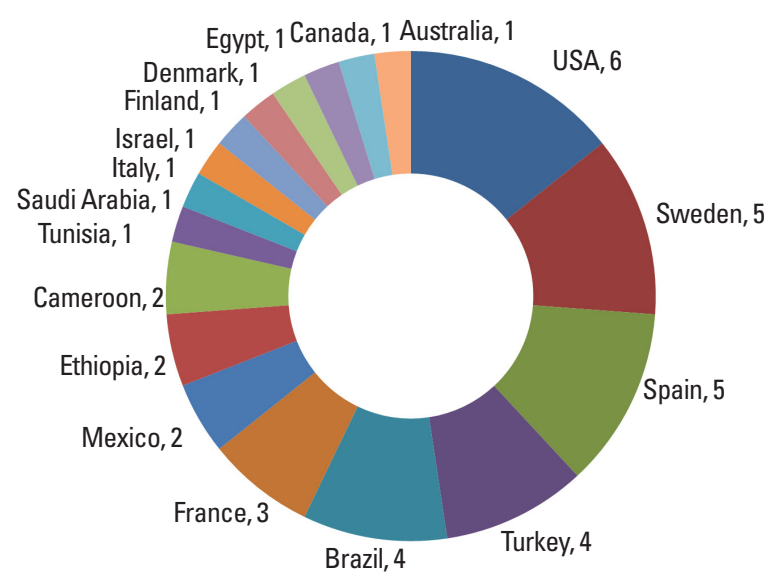

Fig. 3. Countries of the affiliations of the authors of articles published in 2015 and 2016 in the Journal of Exercise Rehabilitation excluding Korea (as of December 3, 2016). Available from: http://e-jer.org/. 


\section{Total: 121}

Number of citations of 2014 articles from Web of Science journals in 2016: 61

Number of citations of 2015 articles from Web of Science journals in 2016: 27

Total: 88

2016 impact factor $=88 / 121=0.727$

The top-ranking countries of the authors who cited the Journal of Exercise Rehabilitation were the USA (62), Korea (47), and China (47). The citations were from 47 countries (Fig. 5). The number of source titles that cited the Journal of Exercise Rehabilitation was 208. Of them, the top-ranking journals were Journal of Physical Therapy Science (11), International Neurourology Journal (9), Biomed Research International (5), Behavioural Brain Research (5), and PLoS One (4).

The H-index was calculated as 7, as indicated in Table 1, which shows the highly-cited articles, their titles, and their publication

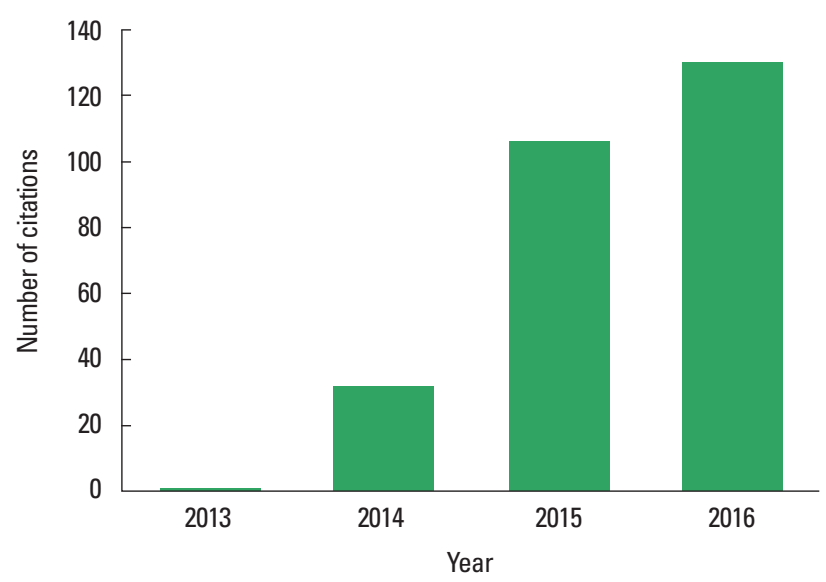

Fig. 4. Number of total citations of the Journal of Exercise Rehabilitation according to year by Web of Science Core Collection journals (as of December 3, 2016). Available from: http://apps.webofknowledge.com/. types. Of the seven most frequently cited articles, four were reviews and three were original articles.

\section{DISCUSSION}

The above results show the rapid promotion of the journal to the international level based on journal metrics during the past 4 years. Defining an international journal is somewhat difficult; however, it has been said that this term means that the journal is read and cited internationally, and that manuscripts are submitted from all over the world. Since the authors became multinational starting in 2015 and articles were cited by authors from 47 countries (Fig. 5), it can be said that the journal reached international status. Furthermore, being at the international level implies meeting additional criteria: first, each article has been edited to precisely fit the style and format of the journal; second, the English is

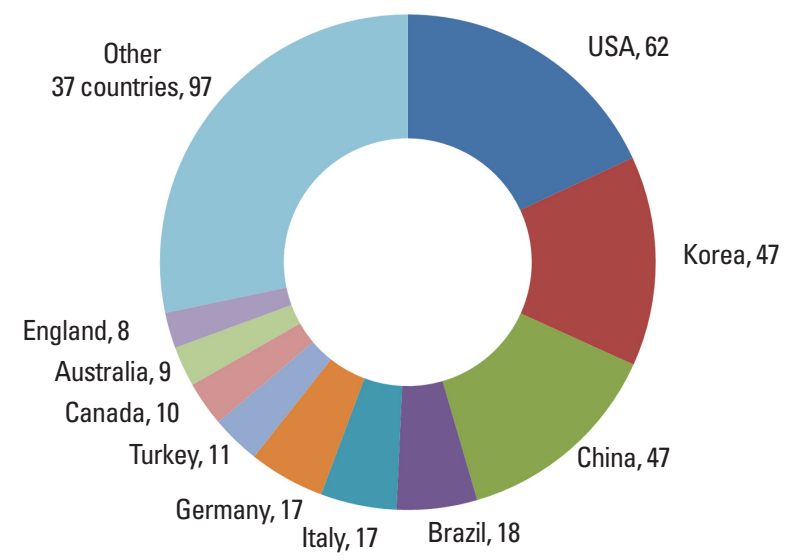

Fig. 5. Number of citations of Journal of Exercise Rehabilitation articles by Web of Science Core Collection journals according to the country of the authors (as of December 3, 2016). Available from: http://apps.webofknowledge. $\mathrm{com} /$.

Table 1. The articles in Journal of Exercise Rehabilitation most frequently cited by Web of Science Core Collection articles (as of December 3, 2016)

\begin{tabular}{|c|c|c|c|c|c|c|}
\hline No. & Year & Vol. & Page & Title & Type & $\begin{array}{l}\text { Times } \\
\text { cited }\end{array}$ \\
\hline 1 & 2014 & 10 & 54 & Role of adiponectin in metabolic and cardiovascular disease & Review & 25 \\
\hline 2 & 2013 & 9 & 338 & Aging, exercise, and extracellular matrix in the heart & Review & 18 \\
\hline 3 & 2013 & 9 & 500 & Exercise rehabilitation for smartphone addiction & Review & 12 \\
\hline 4 & 2014 & 10 & 2 & $\begin{array}{l}\text { Treadmill exercise improves short-term memory by enhancing neurogenesis in amyloid beta-induced } \\
\text { Alzheimer disease rats }\end{array}$ & Original article & 12 \\
\hline 5 & 2013 & 9 & 220 & $\begin{array}{l}\text { Treadmill exercise improves behavioral outcomes and spatial learning memory through up-regulation of } \\
\text { reelin signaling pathway in autistic rats }\end{array}$ & Original article & 11 \\
\hline 6 & 2013 & 9 & 212 & Effects of aging and exercise training on apoptosis in the heart & Review & 7 \\
\hline 7 & 2013 & 9 & 354 & Treadmill exercise alleviates short-term memory impairment in 6-hydroxydopamine-induced Parkinson's rats & Original article & 7 \\
\hline
\end{tabular}

Available from: http://apps.webofknowledge.com/. 
readable, without any fraudulent presentation of the findings; third, its contents are scientifically sound; and fourth, citation metrics are comparable to other journals in the same category (i.e., sport science). The former three items should be determined by the researchers or editors. The fourth item is a quantitative datum that can be calculated using citation databases, such as the Web of Science Core Collection or Scopus.

The tendency in the number of publication per year is a cause for optimism (Fig. 1). It increased recently, and the number of publications by authors from all over the world began to increase in 2015. The incentive for researchers from across the world to submit their manuscripts to the journal is believed to be the inclusion of the journal in PubMed Central in October 2013. Subsequently, submissions from countries other than Korea began to arrive at the editorial office. The publication of 11 articles from 10 countries in 2015 and 24 articles from 15 countries in 2016 excluding Korea is a piece of evidence for internationalization (Fig. 3). Submission from a variety of countries was also due to the fact that the editorial board members are from 11 countries (Fig. 2). The editorial board members usually review the submissions from their countries, and they are eager to recommend colleagues to submit to the journal.

The rapid increase in total citations reflects the usefulness of the articles for researchers and exercise rehabilitation practitioners. More than 100 citations occurred in 2015 (Fig. 4). The high proportion of citations from the USA and China is due to the fact that many publications were from these countries. Frequent citations by Korean researchers might be the result of their concern with the content itself, because the data of many studies were obtained from Korean participants (Fig. 5). Citations from 208 journal titles were another piece of evidence of interest from many journals with a wide range of scope.

The manually calculated impact factor of 2015 (0.912) corresponds to a Journal Citation Reports (JCR) ranking of $24.4 \%$ out of the 82 journals in the category of sport science. If self-citations were excluded, the JCR ranking became $32.9 \%$. The impact factor of $2016(0.727)$ may increase, and should therefore be recalculated at the end of May 2017. It is anticipated to increase to around 1.0. The median value of the impact factor without journal self-citations in the category of sport science in 2015 was 1.352. The journal will be able to reach this median value in the near future due to the devotion of the editors and support from the publisher.

Although the $\mathrm{H}$-index was suggested as a way of evaluating researchers' performance, it is widely used to assess the performance of journals or organizations. An H-index of 7 is a respectable result (Table 1). After changing its language and title name, 4 years is not long enough for a journal to acquire an internationally wellknown brand. Other journals from Korea have a range of $\mathrm{H}$-index scores: 7 over the course of 5 years for Neurointervention (Huh, 2016d); 12 over the course of 6 years for the Journal of Gastric Cancer (Huh, 2016c); 2 over the course of 36 years for the Korean Journal of Child Studies (Huh, 2016b); 13 over the course of 7 years for Clinics in Orthopedic Surgery (Huh, 2016a); 5 over the course of 10 years for the Journal of Educational Evaluation for Health Professions (Huh, 2015b); 9 over the course of 5 years for Annals of Rehabilitation Medicine (Huh, 2015d); 6 over the course of 4 years for Clinical Endoscopy (Huh, 2015a); 11 over the course of 56 years for the Korean Journal of Urology (Huh, 2015c); 6 over the course of 4 years for Clinical and Experimental Reproductive Medicine (Huh, 2014d); 6 over the course of 3 years for Archives of Plastic Surgery (Huh, 2014b); 9 over the course of 4 years for Diabetes $\mathcal{E}$ Metabolism Journal (Huh, 2014c); 6 over the course of 4 years for International Neurourology Journal (Huh, 2014a); and 15 over the course of 28 years for the Korean Journal of Internal Medicine (Huh, 2013a). The most frequently cited publications are usually review articles (Huh, 2015a; Huh, 2015b; Huh, 2016c), although original articles have been cited more frequently than review articles in some journals (Huh, 2015c; Huh, 2015d; Huh, 2016d; Huh, 2016a). In this journal, review articles were cited most frequently.

What is the next step for the journal to be promoted to a top-ranking brand journal in sports science? First, it should be listed in Directory of Open Access Journals in order to be recognized as an open-access journal by Clarivate Analytics. This is possible by making a request using the Journal Application Form (https://doaj.org/application/new). Another strategy for promotion is to cooperate with scholarly societies worldwide whose major concern is exercise rehabilitation. In the Science Citation Index-Expanded (SCIE) journal list from JCR, only 4 journals were found in the field of exercise rehabilitation: the Journal of Rehabilitation Medicine from Sweden; and the Journal of Sport Rebabilitation, American Journal of Physical Medicine \& Rebabilitation, and Archives of Physical Medicine and Rehabilitation from the USA. Additionally, in PubMed Central, BMC Sports Science, Medicine and Rehabilitation and Sports Medicine, Arthroscopy, Rehabilitation, Therapy \& Technology: SMARTT were listed. Both are published by BioMed Central. Therefore, this journal is well-positioned to cooperate with other scholarly societies worldwide. If multiple other scholarly societies participate in this journal as coofficial publishers, it would be the fastest way to broaden the authors' and editorial board members' 
representativeness across countries. Additionally, this would lead to a greater chance of recruiting unique results from a variety of countries. Third, adopting new digital technology is necessary to provide the content to the audience of the journal more easily. An audio recording of the abstract (Huh, 2013b), a brief slide presentation of the content, video presentation of the methods, and podcasts should be considered. Fourth, providing smartphone and smartpad versions of the journal is another way to increase the accessibility of the journal. Finally, although it is not mandatory for journal promotion, applying to a variety of databases such as Medline, Scopus, and Science Citation Index Expanded (SCIE) is necessary. If the journal is listed in Scopus or SCIE, it is possible to characterize its journal metrics very easily; therefore, it is possible to identify the journal's status in the world journal market. I believe that this journal will succeed due to its unique focus on the intersection of sport science and rehabilitation medicine. The necessity of exercise rehabilitation will increase continuously due to increased engagement in sports and exercise activities for a high quality of life and longer life expectancy.

\section{CONFLICT OF INTEREST}

No potential conflict of interest relevant to this article was reported.

\section{ACKNOWLEDGMENTS}

This research was supported by the Hallym University Research Fund (HRF-G-2015-4).

\section{REFERENCES}

Hirsch JE. An index to quantify an individual's scientific research output. Proc Natl Acad Sci U S A 2005;102:16569-16572.

Huh S. Clinics in Orthopedic Surgery's evolution into an international journal based on journal metrics. Clin Orthop Surg 2016a;8:127-132.
Huh S. Evidence of the Internationalization of Clinical Endoscopy based on journal metrics. Clin Endosc 2015a;48:317-321.

Huh S. How far has the International Neurourology Journal progressed since its transformation into an English language journal? Int Neurourol J 2014a;18:3-9.

Huh S. How far has the Korean Journal of Internal Medicine advanced in terms of journal metrics? Korean J Intern Med 2013a;28:635-638.

Huh S. How journal metrics illustrate the transformation of Archives of Plastic Surgery into an international journal. Arch Plast Surg 2014b;41: 617-619.

Huh S. How much is Journal of Educational Evaluation for Health Professions promoted based on journal metrics? J Educ Eval Health Prof 2015b;12:57.

Huh S. How much progress has been made in journal metrics two years after the citation analysis of the Korean Journal of Urology? Korean J Urol 2015c;56:276-279.

Huh S. How to promote the Korean Journal of Child Studies to an international journal. Korean J Child Stud 2016b;37:7-16.

Huh S. Journal metrics-based position of Diabetes \& Metabolism Journal after the change of its text language to English. Diabetes Metab J 2014c;38:187-193.

Huh S. Journal of Gastric Cancer's Promotion to international journal from the perspective of biliometric analysis. J Gastric Cancer 2016c; 16:8-13.

Huh S. Promotion of Neurointervention to international journal based on journal metrics. Neurointervention 2016d;11:5-9.

Huh S. Revision of the instructions to authors to require a structured abstract, digital object identifier of each reference, and author's voice recording may increase journal access. J Educ Eval Health Prof 2013b;10:3.

Huh S. The elevation of Annals of Rehabilitation Medicine to the status of an international journal after adopting an English-only policy. Ann Rehabil Med 2015d;39:661-666.

Huh S. What is the position of Clinical and Experimental Reproductive Medicine in its scholarly journal network based on journal metrics? Clin Exp Reprod Med 2014d;41:147-150. 